\title{
Echocardiography of isolated subacute left heart tamponade in a patient with cor pulmonale and circumferential pericardial effusion
}

\author{
Tomaž Marš , Helena Mikolavčič², Barbara Salobir ${ }^{3}$, Matej Podbregar ${ }^{2 *}$
}

\begin{abstract}
Patients with advanced idiopathic pulmonary artery hypertension have often a chronic pericardial effusion. It is the result of increased transudation and impaired re-absorption due to elevated venous pressure. These patients have pre-existent symptoms and signs of chronic right heart failure. High degree of suspicion is required to detect of development of an atypical form of tamponade with isolated compression of left heart chambers as shown in present case report. Transthoracic echocardiography provides a rapid access to the correct diagnosis, a prompt relief of symptoms following the ultrasound guided pericardiocentesis and important diagnostic tool for regular follow up of patients thereafter as shown in our case report.
\end{abstract}

\section{Background}

Circumferential pericardial effusion typically results in biventricular tamponade and equalization of intracardiac and pericardial pressure during diastole. In classic subacute tamponade the rising of pericardial pressure causes a progressive collapse of right atrium and ventricle preventing venous return to the right atrium. Symptoms and signs referable to increased filling pressure and diminished cardiac output ensue. Patients presents with dyspnea, orthopnea, peripheral edema, fatigability, hepatic engorgement. The three principal features: jugular venous distention, soft or absent heart sounds and hypotension (Beck's triad), tachycardia and pulsus paradoxus are present. However, tamponade may involve the right or left heart. While isolated left ventricular tamponade can occur as a postoperative complication form localized posterior pericardial effusions or hematoma, circumferential pericardial effusions leading to left heart tamponade are rare [1].

\section{Case presentation}

We present a clinical course and echocardiographic examination in a patient with idiopathic pulmonary artery hypertension (IPAH) and chronic pericardial

\footnotetext{
* Correspondence: matej.podbregar@guest.arnes.si

${ }^{2}$ Clinical Department for Internal Intensive Care, University Medical Center
} Ljubljana, Slovenia

C 2010 Marš et al; licensee BioMed Central Ltd. This is an Open Access article distributed under the terms of the Creative Commons Attribution License (http://creativecommons.org/licenses/by/2.0), which permits unrestricted use, distribution, and reproduction in any medium, provided the original work is properly cited. effusion who developed a subacute isolated left heart tamponade.

A 57-year-old patient with IPAH and a previously known chronic pericardial effusion presented in an outpatient clinic with symptoms of dyspnea on exertion, in the last days even at rest, ortopnea and leg edema. During the past few months he was in good physical condition. He was on therapy with sildenafil, amlodipine, acenocoumarol and had a combination inhaler containing fluticasone propionate and salmeterol xinafoate. The clinical examination showed distended jugular veins, leg edema and an accentuated second heart sound. A chest radiogram showed an enlarged heart shadow. The echocardiographic examination showed a dilated right atrium and ventricle (Figure 1) with reduced ejection fraction, severe tricuspid insufficiency (Figure 2), systolic right ventricular pressure $82 \mathrm{~mm} \mathrm{Hg}$ plus central venous pressure (Figure 3 ), the inferior vena cava larger than $2.5 \mathrm{~cm}$ with no respiration variability. Clinically estimated central venous pressure was approximately $20 \mathrm{~mm} \mathrm{Hg}$. Compared with the previous transthoracic echocardiographic examination, there was enlarged pericardial effusion, $3 \mathrm{~cm}$ behind the left ventricular posterior (Figure 4) wall with diastolic collapse of left atrium and ventricle (Additional files 1, 2 and 3).

After the normalisation of the haemosthasis with fresh frozen plasma echocardiographicly guided pericardiocentesis using a parsternal approach was performed. 


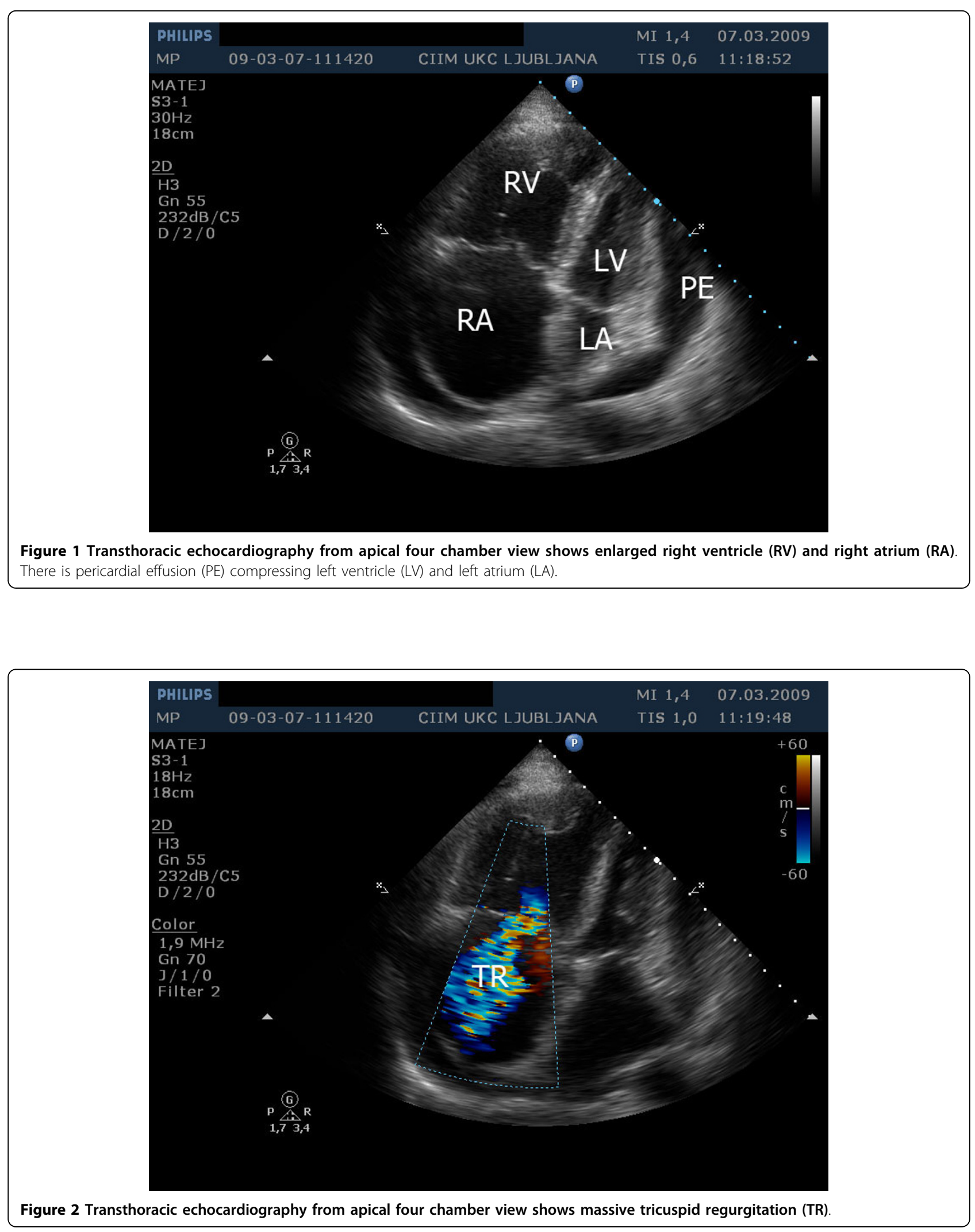



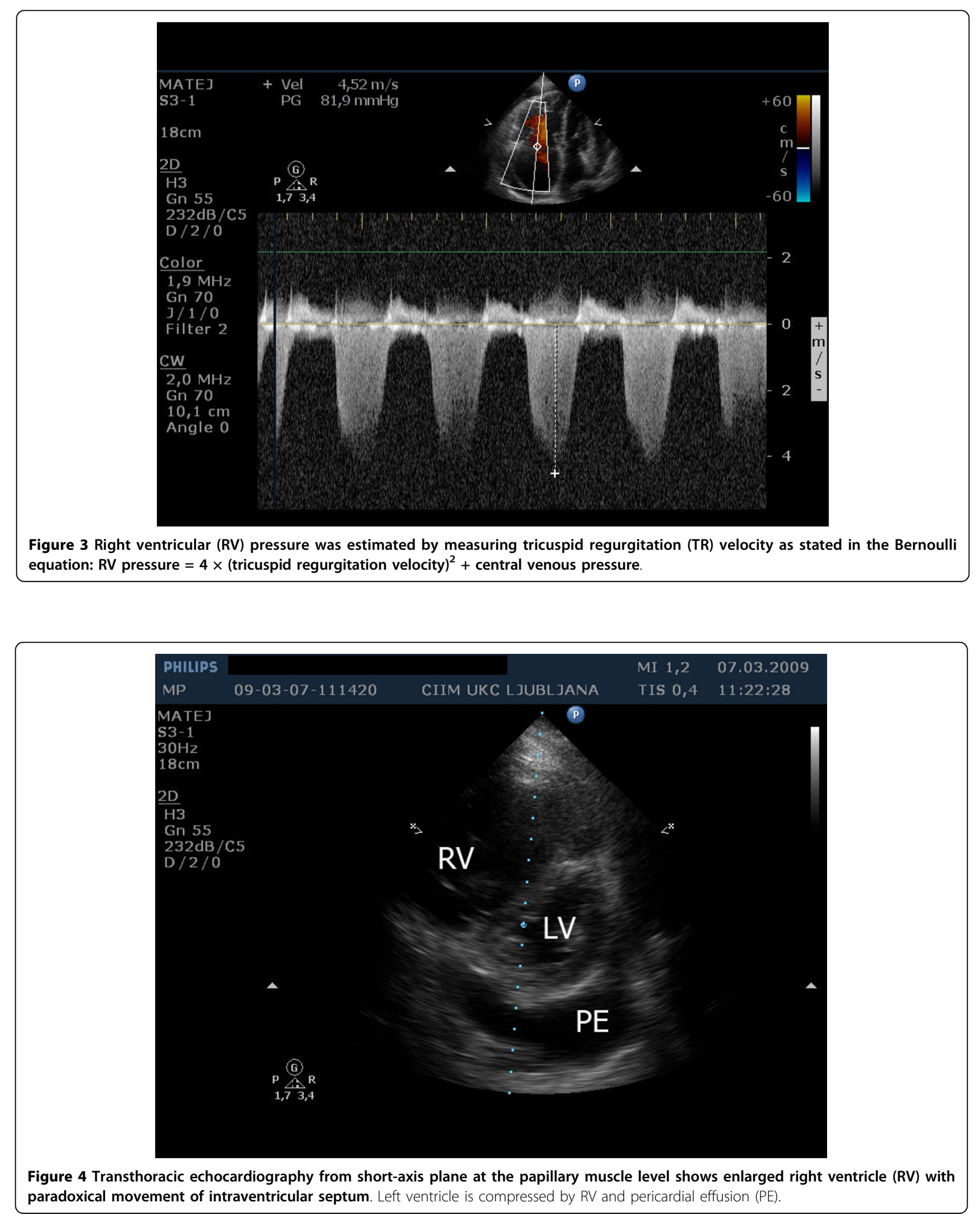
Immediately after removal of $250 \mathrm{ml}$ of yellow fluid the patient became normopnoic. There was still $1.5 \mathrm{~cm}$ large pericardial effusion behind the left ventricular posterior wall without left heart collapse (Additional file 4).

The pericardial fluid was a borderline transudate with slightly elevated proteins. Cytological studies for malignancy, microbiological microscopic examination and cultures (included Mycobacterium tuberculosis) were negative. Rheumatic markers (antinuclear antibodies, anti-double-strand DNA, anticardiolipin antibodies, lupus anticoagulants, rheumatoid factor), angiotensinconvertyng enzyme and tumor markers (tissue polypeptide antigen, neuron-specific enolase, alpha-fetoprotein, prostate-specific antigen, carcinoembryonic antigen) were all in normal range. The function of the thyroid gland was normal.

\section{Discussion}

Patients with cor pulmonale and circumferential pericardial effusion develop an atypical form of cadiac tamponade with isolated left heart compression. Pre-existing pulmonary arterial hypertension can modify the classic presentation. Symptoms and signs of right heart failure could already be present, so a high index of suspicion for tamponade is required in every worsening of right heart failure symptoms. When the pericardial pressure starts to increase in a patent with cor pulmonale, elevated pressure in right heart chambers prevent right atrial and ventricular compression, but while the pericardial pressure rises to the point to exceed left chambers pressure, this results first in diastolic collapse of left atrium and later on in left ventricle collapse due to a transient reversal of the transmural pressure [2,3]. Signs of impaired filling of left ventricle ensue leading to a drop in cardiac output.

The most probable mechanism of accumulation of pericardial fluid in patients with IPAH is transudation and impaired re-absorption of pericardial fluid due to elevated venous hydrostatic pressure in the setting of cor pulmonale.

In the setting of pulmonary arterial hypertension large hemodynamically significant pericardial effusions might be treated surgically and/or conservative and it is known that prognosis of patients with this complication is poor $[4,5]$. However, our patient has been stable throughout one year period after pericardiocentesis on his regular therapy after titration of diuretic furosemide (one tablets of $40 \mathrm{mg}$ two to four times weekly) according to signs of right heart failure and measurements of NT-pro BNP (NT-proBNP before $600 \mathrm{ng} / \mathrm{L}$, at the time of detection $1029 \mathrm{ng} / \mathrm{L}$ and one year after detection of circumferential pericardial effusion $601 \mathrm{ng} / \mathrm{L}$ ). Additional regular repeated echocardiographic examinations were performed.
The right ventricle-to-right atrial pressure gradient may be difficult to estimate in the setting of severe tricuspid regurgitation, when there is a large color flow regurgitant jet. In this case, the peak velocity may not reflect the true pressure gradient.

In conclusion, patients with advanced IPAH have often a chronic pericardial effusion. It is the result of increased transudation and impaired re-absorption due to elevated venous pressure. These patients have preexistent symptoms and signs of chronic right heart failure. High degree of suspicion is required to detect of development of an atypical form of tamponade with isolated compression of left heart chambers. Transthoracic echocardiography provides a rapid access to the correct diagnosis, a prompt relief of symptoms following the ultrasound guided pericardiocentesis and important diagnostic tool for regular follow up of patients thereafter.

\section{Consent}

Written informed consent was obtained from the patient for publication of this case report and accompanying images. A copy of written consent is available for review by the Editor-in-Chief of this journal.

\section{Additional material}

Additional file 1: Transthoracic echocardiography from apical four chamber view shows enlarged right ventricle (RV) and right atrium (RA). There is pericardial effusion (PE) compressing left ventricle (LV) and left atrium (LA).

Additional file 2: Transthoracic echocardiography from short-axis plane at the papillary muscle level shows enlarged right ventricle (RV) with paradoxical movement of intraventricular septum. Left ventricle is compressed by RV and pericardial effusion (PE).

Additional file 3: Transthoracic echocardiography from apical four chamber view shows enlarged right ventricle (RV) and tricuspid regurgitation (TR).

Additional file 4: Transthoracic echocardiography from apical four chamber view after pericardiocentesis. Right ventricle (RV), right atrium (RA), left ventricle (LV), left atrium (LA).

\section{Author details}

${ }^{1}$ Institute of Pathophysiology, Faculty of Medicine, University of Ljubljana, Slovenia. ${ }^{2}$ Clinical Department for Internal Intensive Care, University Medical Center Ljubljana, Slovenia. ${ }^{3}$ Clinical Department for Pulmonary Disease and Alergology, University Medical Center Ljubljana, Slovenia.

\section{Authors' contributions}

TM: carried out interpretation and drafted the manuscript HM: carried out interpretation and drafted the manuscript BS: treated the patient, carried out interpretation and drafted the manuscript MP: treated the patient, made acquisition of data, carried out interpretation and drafted the manuscript

All authors read and approved the final manuscript.

\section{Competing interests}

The authors declare that they have no competing interests. 


\section{References}

1. Chuttani K, Pandian NG, Mohanty PK, Rosenfield K, Schwartz SL, Udelson JE, Simonetti J, Kusay BS, Caldeira ME: Left ventricular diastolic collapse. An echocardiographic sign of regional cardiac tamponade. Circulation 1991, 83:1999-2006.

2. Frey MJ, Berko B, Palevsky H, Hirshfeld JW Jr, Herrmann HC: Recognition of cardiac tamponade in the presence of severe pulmonary hypertension. Ann Intern Med 1989, 111:615-617.

3. Gollapudi RR, Yeager M, Johnson AD: Left ventricular cardiac tamponade in the setting of cor pulmonale and circumferential pericardial effusion. Case report and review of the literature. Cardiol Rev 2005, 13:214-217.

4. Aqel RA, Aljaroudi W, Hage FG, Tallaj J, Raybum B, Nanda NC: Left ventricular collapse secondary to pericardial effusion treated with pericardiocentesis and percutaneus pericardiotomy in severe pulmonary hypertension. Echocardiography 2008, 6:658-61.

5. Hemmes AR, Gaine SP, Wiener CM: Poor outcomes associated with drainage of pericardial effusions in patients with pulmonary arterial hypertension. South Med 2008, 5:490-4.

doi:10.1186/1476-7120-8-27

Cite this article as: Marš et al:: Echocardiography of isolated subacute left heart tamponade in a patient with cor pulmonale and circumferential pericardial effusion. Cardiovascular Ultrasound 2010 8:27.

\section{Submit your next manuscript to BioMed Central and take full advantage of:}

- Convenient online submission

- Thorough peer review

- No space constraints or color figure charges

- Immediate publication on acceptance

- Inclusion in PubMed, CAS, Scopus and Google Scholar

- Research which is freely available for redistribution

Submit your manuscript at www.biomedcentral.com/submit 